\title{
The role of the carboxyl terminus in folding of the serotonin transporter
}

\author{
Ali El-Kasaby", Herwig Just, Harald Sitte, Oliver Kudlacek, Michael Freissmuth \\ From 16th Scientific Symposium of the Austrian Pharmacological Society (APHAR) \\ Vienna, Austria. 25-27 November 2010
}

\section{Background}

The serotonin transporter (SERT) is a member of the SLC6 family of solute carriers. SERT plays a crucial role in synaptic neurotransmission by retrieving released serotonin. The intracellular carboxyl terminus of various neurotransmitter transporters has been shown to be important for the correct delivery of SLC6 family members to the cell surface. A previous study showed that deleting the C-terminus of SERT impaired transporter activity and compromised its delivery to the plasma membrane [1], but this study did not offer any mechanistic explanation for these effects. The hypothesis of the current project has been that the C-terminus of SERT is required for folding and trafficking of the serotonin transporter.

\section{Materials and methods}

We employed several approaches to examine the given hypothesis, including (1) serial truncations of the carboxyl terminus, (2) scanning the C-terminus of SERTs for motifs that are required for expression of functional transporter, (3) localization by confocal laser scanning microscopy, biochemical characterization (binding studies, uptake studies), (4) bacterial expression of SERT with a C-terminally fused GFP tag [2], (5) coimmunoprecipitation of the misfolded mutant with calnexin [3], and (6) test for possible chemical and pharmacological chaperone effects of SERT.

\section{Results}

Here we studied the importance of the C-terminus in trafficking and folding of human SERT. Serial truncations followed by mutagenesis identified sequence spots

\footnotetext{
* Correspondence: ali.el-kasaby@meduniwien.ac.at Institute of Pharmacology, Center of Physiology and Pharmacology, Medical University of Vienna, 1090 Vienna, Austria
}

$\left(\mathrm{PG}^{601,602}, \mathrm{RII}^{607-609}\right)$ within the C-terminus relevant for export of SERT from the endoplasmic reticulum (ER). $\mathrm{RI}^{607,608}$ is homologous to the RL-motif that in other SLC6 family members provides a docking site for the COPII component Sec24D. The primary defect resulting from mutation at $\mathrm{PG}^{601,602}$ and $\mathrm{RI}^{607,608}$ was impaired folding, because mutated transporters failed to bind the inhibitor $\left[{ }^{3} \mathrm{H}\right]$ imipramine. In contrast, when retained in the ER (e.g. by dominant negative Sar1) the wild-type transporter bound $\left[{ }^{3} \mathrm{H}\right]$ imipramine with an affinity comparable to surface-expressed transporter. SERT$\mathrm{RI}^{607,608} \mathrm{AA}$ and SERT-RII ${ }^{607-609}$ AAA were partially rescued by treatment of cells with the nonspecific chemical chaperone DMSO or the specific pharmacochaperone ibogaine (which binds to the inward-facing conformation of SERT) but not by other classes of ligands (inhibitors, substrates, amphetamines).

\section{Conclusions}

These observations (i) demonstrate a hitherto unappreciated role of the $\mathrm{C}$-terminus in the folding of SERT, (ii) indicate that the folding trajectory proceeds via an inward-facing intermediate and (iii) suggest a model where the RI-motif plays a crucial role in preventing premature Sec24-recruitment and export of incorrectly folded transporters.

\section{Published: 16 November 2010}

\section{References}

1. Larsen MB, Fjorback AW, Wiborg O: The C-terminus is critical for the functional expression of the human serotonin transporter. Biochemistry 2006, 45:1331-1337.

2. Waldo GS, Standish BM, Berendzen J, Terwilliger TC: Rapid protein-folding assay using green fluorescent protein. Nat Biotechnol 1999, 17:691-695. 
3. Duvernay MT, Dong C, Zhang X, Zhou F, Nichols CD, Wu G: Anterograde trafficking of $\mathrm{G}$ protein-coupled receptors: function of the C-terminal $\mathrm{F}(\mathrm{X}) 6 \mathrm{LL}$ motif in export from the endoplasmic reticulum. Mol Pharmacol 2009, 75:751-761.

doi:10.1186/1471-2210-10-S1-A18

Cite this article as: El-Kasaby et al:: The role of the carboxyl terminus in folding of the serotonin transporter. BMC Pharmacology 2010 10(Suppl 1): A18.

Submit your next manuscript to BioMed Central and take full advantage of:

- Convenient online submission

- Thorough peer review

- No space constraints or color figure charges

- Immediate publication on acceptance

- Inclusion in PubMed, CAS, Scopus and Google Scholar

- Research which is freely available for redistribution 